\title{
二维 $\mathrm{GeSe}_{2}$ 面内各向异性及短波偏振光探测研究
}

刘忠范

北京大学化学与分子工程学院, 北京 100871

\section{In-Plane Anisotropic $\mathrm{GeSe}_{2}$ for Short-Wave Polarization-Sensitive Photodetection}

\section{LIU Zhongfan}

College of Chemistry and Molecular Engineering, Peking University, Beijing 100871, P. R. China.

Email: zfliu@pku.edu.cn
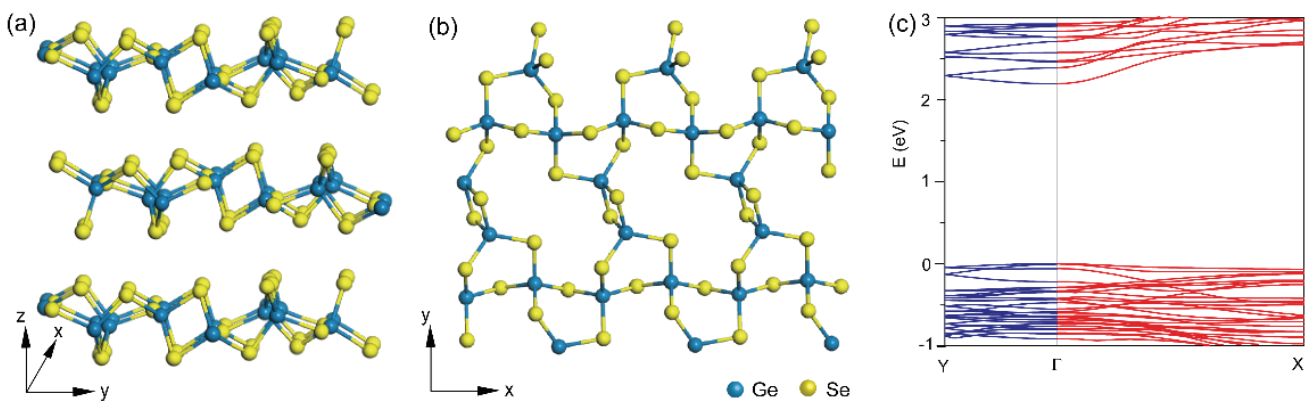

(d)
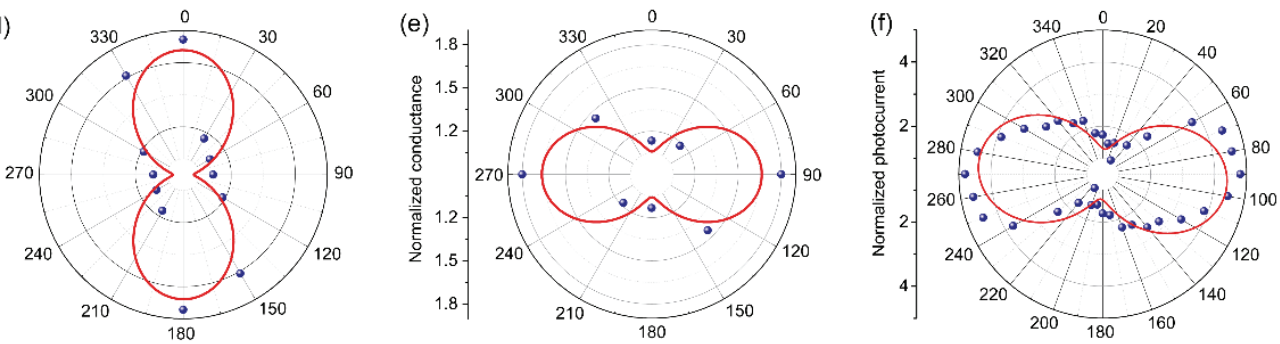

(a) $\mathrm{GeSe}_{2}$ 晶体结构侧视图; (b) $\mathrm{GeSe}_{2}$ 晶体结构俯视图; (c) $\mathrm{GeSe}_{2}$ 能带结构图; (d) $\mathrm{GeSe}_{2}$ 角分辨拉曼强度的极坐标图 (拉曼位移峰 $210 \mathrm{~cm}^{-1}$ ); (e) $\mathrm{GeSe}_{2}$ 角分辨归一化电导的极坐标图(四对电极); (f) 不同方向线偏振光 $(450 \mathrm{~nm})$

照射下角分辨归一化光电流的极坐标图。

作为一种新型的二维半导体材料, 黑磷因其独 特的面内各向异性引起了研究人员的广泛关注 ${ }^{1}$ 。近 期, 几种其它面内各向异性二维材料(如 $\mathrm{ReS}_{2}$ 、 $\mathrm{ReSe}_{2} 、 \mathrm{SnS} 、 \mathrm{GeSe}$ 等)也被相继报道 ${ }^{2-5}$ 。此类材 料独特的面内各向异性使其区别于以往的石墨 烯、 $\mathrm{MoS}_{2}$ 等面内各向同性二维材料, 表现出特殊 的电学、光学、机械和热学性能, 并被成功应用于 集成电路中的反相器、基于晶向的二极管、人造突 触和偏振光光电探测器等器件中 ${ }^{6}$ 。其中, 偏振光
探测由于在通信中的重要地位, 被认为是近年来 非常有发展潜力的一个研究领域。目前, 基于黑 磷、 $\mathrm{ReS}_{2} 、 \mathrm{GeSe}$ 等面内各向异性材料的偏振光探 测虽性能优异, 但因上述材料带隙均较小 $(<2 \mathrm{eV})$, 在进行短波段光偏振探测时还需复杂及昂贵的光 学系统将其理想的光探范围调至短波段。

中国科学院化学研究所胡劲松研究员课题组 与北京大学张耿民教授课题组等近期一起提出一 种具有较宽带隙的面内各向异性材料- $\mathrm{GeSe}_{2}$ 
$(2.74 \mathrm{eV})$, 通过理论计算和实验系统研究了该材料 的面内结构、振动、电学和光学的各向异性性质, 并基于其光学吸收各向异性构筑了新型 $\mathrm{GeSe}_{2}$ 偏 振光光电探测器, 首次报道了其在短波段光偏振 探测方面的应用。由于良好的性能和空气稳定性, $\mathrm{GeSe}_{2}$ 偏振光探测器展现出良好的应用前景。相关 研究成果发表在近期的 Journal of the American

Chemical Society ${ }^{7}$ 。

$\mathrm{GeSe}_{2}$ 是一种典型的 IV-VI 族化合物, 有 $\alpha$ 、 $\beta$ 和 $\gamma$ 三种相。该文研究的单斜 $\beta-\mathrm{GeSe}_{2}$ 具有面内 各向异性性质, 是上述三种相中最稳定的一种相, 带隙为 $2.7 \mathrm{eV}$, 吸收系数约 $10^{4} \mathrm{~cm}^{-1}$, 非常适合于 短波段偏振光探测。他们首先通过理论计算研究 了 $\mathrm{GeSe}_{2}$ 沿面内的能带结构, 表明其在 $x$ 方向和 $y$ 方向的空穴有效质量分别为 $\sim 0.755 m_{0}$ 和 $1.562 m_{0}$, 从理论上证实了其面内各向异性。然后, 通过角分 辨拉曼光谱和角分辨电导测试, 显示了其显著的 面内振动和电导各向异性。随后, 基于单个 $\mathrm{GeSe}_{2}$ 纳米片构筑了光电探测器。在不同方向的 $450 \mathrm{~nm}$ 线偏振光照射下表现出显著的光电流差异, 光电 流之比为 3.4 , 体现了该材料在短波区域优异的偏 振光探测性能。最后, 通过实验和密度泛函理论
(DFT)计算表明 $\mathrm{GeSe}_{2}$ 具有较高的吸附氧活化能 $(2.12 \mathrm{eV}$; 远高于黑磷的 $0.71 \mathrm{eV})$, 因而表现优异 的空气稳定性。

\section{References}

(1) Xia, F.; Wang, H.; Jia, Y. Nat. Commun. 2014, 5, 4458. doi: $10.1038 /$ ncomms 5458

(2) Liu, E.; Fu, Y.; Wang, Y.; Feng, Y.; Liu, H.; Wan, X.; Zhou, W.; Wang, B.; Shao, L.; Ho, C. H.; et al. Nat. Commun. 2015, 6, 6991. doi: $10.1038 /$ ncomms 7991

(3) Hafeez, M.; Gan, L.; Li, H.; Ma, Y.; Zhai, T. Adv. Mater. 2016, 28, 8296. doi: 10.1002/adfm.201703858

(4) Tian, Z.; Guo, C.; Zhao, M.; Li, R.; Xue, J. ACS Nano 2017, 11, 2219. doi: 10.1021/acsnano.6b08704

(5) Wang, X.; Li, Y.; Huang, L.; Jiang, X. W.; Jiang, L.; Dong, H.; Wei, Z.; Li, J.; Hu, W. J. Am. Chem. Soc. 2017, 139, 14976. doi: $10.1021 /$ jacs.7b06314

(6) Tian, H.; Tice, J.; Fei, R.; Tran, V.; Yan, X.; Yang, L.; Wang, H. Nano Today 2016, 11, 763. doi: 10.1016/j.nantod.2016.10.003

(7) Yang, Y.; Liu, S. C.; Yang, W.; Li, Z.; Wang, Y.; Wang, X.; Zhang, S.; Zhang, Y.; Long, M.; Zhang, G.; et al. J. Am. Chem. Soc. 2018, doi: 10.1021/jacs.8b01234 